\title{
INDOOR RESIDUAL SPRAYING AND ITS EFFECT ON THE RISK OF MALARIA INFECTION IN CHILDREN UNDER FIVE: A META-ANALYSIS
}

\author{
Arlina Azka'), Setyo Sri Rahardjo²), Bhisma Murti1) \\ ${ }^{1)}$ Masters Program in Public Health, Universitas Sebelas Maret \\ ${ }^{2)}$ Faculty of Medicine, Universitas Sebelas Maret
}

\begin{abstract}
Background: The two most important malaria parasite species are Plasmodium falciparum and Plasmodium vivax. The principal vector of malaria is Anopheles arabiensis, and most vector control activities are targeted against this species. Current malaria prevention and control strategy includes indoor residual spraying (IRS), environmental control use of long-lasting insecticide-treated nets (LLINs), and effective case management. This study was conducted to examine indoor residual spraying and its effect on the risk of malaria infection in children under five.

Subjects and Method: A systematic literature search was conducted in multiple databases including PubMed, Google Scholar, SpringerLink, ResearchGate, and Science Direct and complemented to identify cross-sectional studies published from 2020 to 2011. The following search terms were used: "malaria risk" AND "indoor residual spraying" AND "children under five" AND "cross-sectional". The inclusion criteria were English full-text and reported adjusted odds ratio.

Results: 8 studies from Zambia, Tanzania, Uganda, Nigeria, Sierra Leone, and Ethiopia were involved in meta-analysis. This study showed that children who are lived in the house with indoor residual spraying had a lower risk to expose malaria $(\mathrm{aOR}=$ $0.63 ; 95 \% \mathrm{CI}=0.49$ to $0.79 ; \mathrm{p}<0.001)$.

Conclusion: Indoor residual spraying reduces the risk of malaria in children under five.
\end{abstract}

Keywords: indoor residual spraying, malaria, children under five

\section{Correspondence:}

Arlina Azka. Masters Program in Public Health, Universitas Sebelas Maret. Jl. Ir. Sutami 36A, Surakarta 57126, Central Java. Email: arlina.azka@gmail.com. Mobile: +6281214773660 . 